This is an accepted manuscript.The original article has been publsihed in Technological Forecasting and Social Change. 2017, 118, pp.195-204.

https://doi.org/10.1016/j.techfore.2017.02.020. [T] The Insitutional Repository of University of Tampere

\title{
Replacing centralised waste and sanitation infrastructure with local treatment and nutrient recycling: Expert opinions in the context of urban planning
}

Brief running title: Circular system preconditions

Maarit Särkilahti ${ }^{1}$, Viljami Kinnunen ${ }^{1}$, Riitta Kettunen ${ }^{1}$, Ari Jokinen ${ }^{2}$, Jukka Rintala ${ }^{1}$

${ }^{1}$ Department of Chemistry and Bioengineering, Tampere University of Technology, PO Box 527, FI33101, Tampere, Finland, maarit.sarkilahti@tut.fi (corresponding author)

${ }^{2}$ School of Management, FI-33014, University of Tampere, Tampere, Finland

\begin{abstract}
Solutions for resource scarcity should be sought from urban waste management and sanitation, which are characterised by central plants and long networks. The socio-technical transition to more sustainable infrastructure is expected to include partial decentralisation based on local conditions. This paper focuses on drivers, barriers and enablers in implementing a decentralised circular system in a new residential area (Tampere, Finland). In the alternative system, biowaste and feces are treated in a local biogas plant, and nutrient and energy output are utilised within the area. This research aims to understand what kind of urban planning enables alternative infrastructure, as well as the characteristics of an innovation capable of making a breakthrough. Seventeen infrastructure planning experts were interviewed, then assembled to re-develop ideas arising from the interviews. Based on these qualitatively analysed data, 12 factors which help the adoption of the alternative system were formulated. The results indicate that sustainability transition can be facilitated through impartial urban planning that allows the early participation of actors and improved communications. Additionally, studying the impact of alternative solutions and city guidance according to environmental policy aims may enhance transition. Innovation success factors include suitable locations, competent partners, mature technology and visible local benefits.
\end{abstract}

Keywords: alternative sanitation; biogas; nutrient recycling; urban land-use planning; socio-technical transition; Tampere 


\section{Introduction}

Resource scarcity is a topical issue whose solutions should be sought not only from the energy sector, but also from the waste management/sanitation sector. Currently, urban infrastructures are characterised by centralised treatment plants and long transportation distances, and they have been criticised for high energy and resource usage as well as inadequate resource recycling. The EU has been supporting a circular economy through the Horizon 2020 Research and Innovation programme (Horizon 2020 sections.). Consequently, there are new technical solutions available, but their testing and implementation are still in the initial stage. The adaptation of technical innovations has been resisted by stable infrastructure regimes, which carry out essential societal functions and are therefore characterised by lock-in and path-dependency processes (Smith \& Raven, 2012). In past decades, the centralisation of infrastructures has inevitably provided health and environmental benefits. However, a revival of decentralised urban infrastructures should be considered today to counteract new sustainability challenges.

To understand the present infrastructures and the motivation to change them, technical solutions and resource flows need to be observed critically. At the beginning of the food chain, current agriculture depends on irrigation (Valipour, 2015) and artificial fertilisers produced in an energyintensive process (nitrogen N) (Brentrup \& Palliére, 2008) and mined from scarce reserves (phosphorus P) (Cordell, Drangert, \& White, 2009). Agricultural products, and consequently food products, contain high amounts of nutrients that the human body mainly excretes in urine (Spångberg, 2014). In addition, garden and kitchen waste (hereafter referred to as biowaste) contributes to urban nutrient flow (Sokka, Antikainen, \& Kauppi, 2004). In a conventional wastewater-treatment plant, energy and chemicals are used to remove nutrients according to ever stricter environmental requirements. In wastewater treatment, $\mathrm{N}$ is converted to atmospheric nitrogen and $\mathrm{P}$ is often precipitated into an insoluble form, limiting its reuse. Finally, biowaste and treated sewage sludge are landfilled, incinerated, composted, anaerobically digested (Manfredi \& Pant, 2011) and/or recycled into agriculture.

Anaerobic digestion is an attractive treatment technology because it generates renewable energy in the form of biogas, supports nutrient recycling and potentially creates local jobs. Furthermore, anaerobic digestion is suitable for urban areas because the process occurs in enclosed tanks, and emissions are easier to manage than in other treatment methods (Edwards, Othman, \& Burn, 2015). However, recycling end products from centralised plants to agriculture is marginal (Meers, 2016), so the nutrient loop is not closed. In addition to process limitations, the risk of recycling harmful substances, lack of acceptability (Aubain et al., 2002), unsupportive or unclear legal frameworks (Hukari, Hermann, \& Nättorp, 2016), and governance aspects such as poor source-separation or inefficient plant operation (Zabaleta \& Rodic-Wiersma, 2015) are hindering the recycling of wastederived nutrients.

Source-separating sanitation and decentralised treatment of domestic wastewater have been suggested as an alternative with the potential to improve nutrient recycling and energy efficiency in the sanitation system (Tervahauta, Hoang, Hernández, Zeeman, \& Buisman, 2013). Furthermore, decentralised water systems have the potential to reduce infrastructure costs and support innovations that can be exported to emerging economies (Quezada, Walton, \& Sharma, 2016), whereas distributed energy systems may increase renewable energy production capacity and energy 
self-sufficiency (Ruggiero, Varho, \& Rikkonen, 2015); moreover, such systems may enhance sustainability in terms of flexibility, locality and networking (Alanne \& Saari, 2006). To promote local resource cycles and renewable energy production, the authors have designed a decentralised circular system (Figure 2, in section 2.2) that consists of source-separating low-water toilets, smallscale biogas plants, and the local utilisation of nutrients and produced gas within a residential area (the case city: Tampere, Finland).

In addition to technological advancements, planning in diverse forms is required to improve urban infrastructures. The most comprehensive is land-use planning, which coordinates sectoral policies and decisions with spatial impacts. Planning systems vary between countries. In Finland, municipalities have a planning monopoly, as well as the power to approve and ratify master plans and detailed plans (Finnish Parliament, 1999). Stakeholder participation and sustainable development are emphasised in planning legislation. As a complementary planning instrument, cities use unofficial land-use planning based on public-private partnerships (Junnila, Niiranen, Majamaa, \& Kuronen, 2010). This increases their strategic capacity and flexibility to react to new possibilities. In addition, land policy is an important resource for cities in their planning. At the moment, more instruments and cooperation are needed in Finland for integrated planning between administrative sectors and between municipalities (Hirvonen-Kantola \& Mäntysalo, 2014). Related to these challenges, it is worth noting that land-use planning is determined not only by legal and administrative rules, but also by informal institutions. Political, socio-economic and cultural forces affect the planning system.

In this paper, the objective is to determine the preconditions for implementing the decentralised circular system. The authors explored the system's feasibility in semi-structured interviews with 17 water-, waste-, gas-, energy-, and urban land-use planning experts, and in a workshop with seven experts. In directed content analysis (Hsieh \& Shannon, 2005), drivers, barriers and enablers (Quezada et al., 2016) for alternative system implementation were sought. The results were organised based on a multi-level perspective (MLP) (Geels, 2010) that views socio-technical transition as an interaction between three levels: niches (novelty), regime (dominant actors, institutions and technologies) and landscape (political environment). The authors aim was to answer the following research questions:

A) How can a decentralised circular system be supported in the context of urban planning?

B) What are the characteristics of an alternative system capable of achieving a breakthrough?

Previous research has generated knowledge on various aspects of sustainable urban infrastructure (Ferrer, Thomé, \& Scavarda, 2016), but a gap remains between infrastructure planning scholarship and the realities of public infrastructure planning (Malekpour, Brown, \& de Haan, 2015). The decentralised circular system considered in this paper and placed in the context of urban land-use planning contributes to fulfilling this research gap. Another contribution of the paper is to introduce the innovative methodology of using expert opinions to investigate the preconditions of an alternative infrastructure. 


\section{Material and methods}

\subsection{Multilevel perspective on the research setting}

The authors organised the preconditions for implementing the decentralised circular system in a new residential area according to a multilevel perspective. In MLP, landscape refers to an exogenous environment that changes slowly and affects niche and regime dynamics (Verbong \& Geels, 2010). This study is motivated by global resource scarcity and aims to enhance sustainability, liveability (de Haan et al., 2014) and the circular economy (Figure 1), which questions the performance of current regimes and generates opportunities for the studied system. On the other hand, there are also opposite landscape processes, including strong consumption culture, which fit with current regimes and may hinder transitio

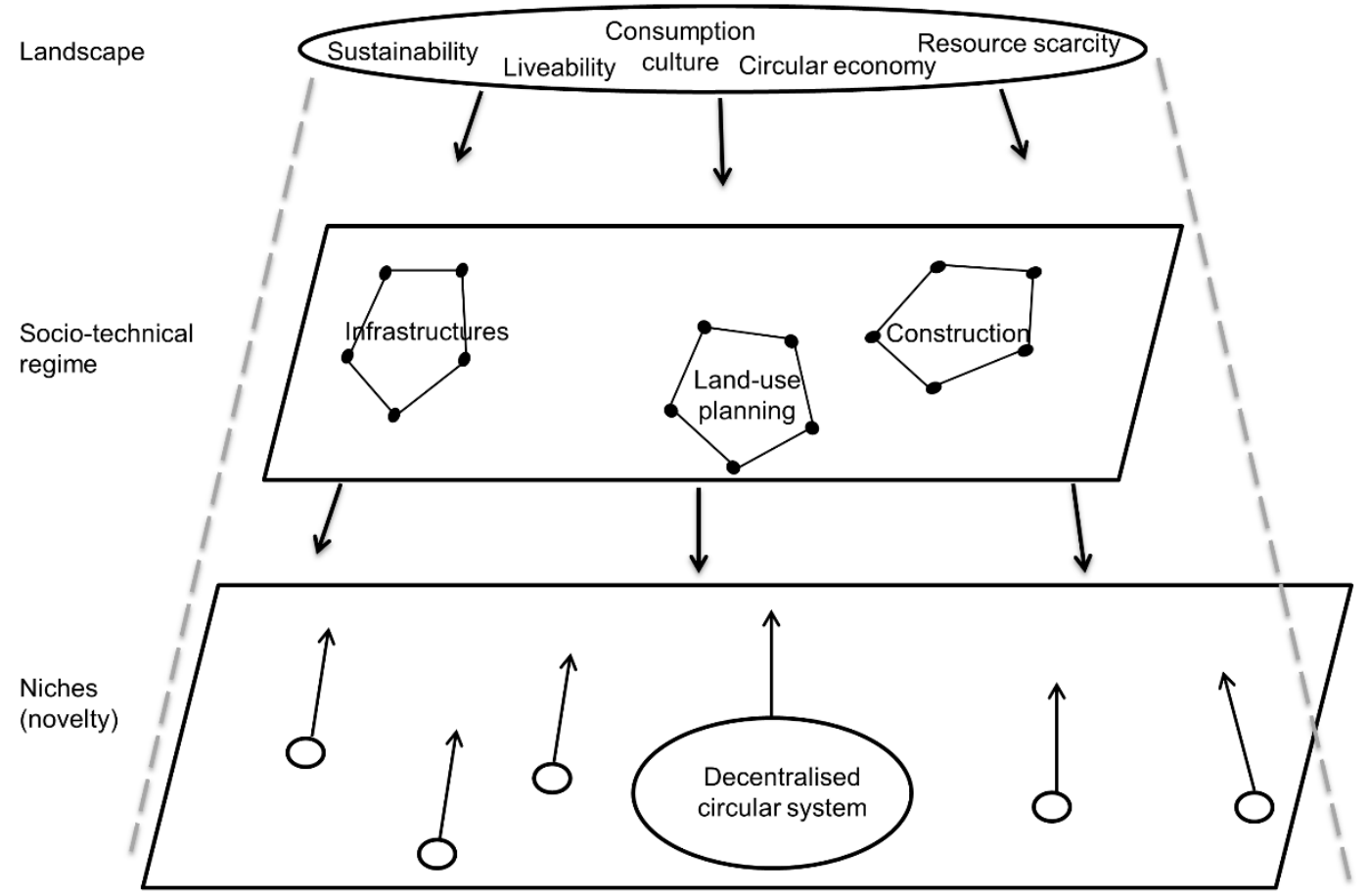

Figure 1. A decentralised circular system (niche); dominant actors, institutions and technologies in infrastructure development (regime); and external factors (landscape), such as lifestyles and political ambitions, which shape cities. Multiple levels were adopted from Geels (2010).

Regimes are the prevailing means for realising key societal functions (Smith, Voß, \& Grin, 2010); they consist of material and technical elements, networks of actors, and rules that guide activities (Verbong \& Geels, 2010). In the context of this paper, regimes include municipal water, sanitation and waste infrastructure. When an (alternative) infrastructure is realised in new residential areas, the strongest actors come from municipal land-use planning, where the planning power is, and from construction companies, which invest in building houses (Figure 1). Characteristically, infrastructure sectors are highly institutionalised socio-technical regimes that enable certain rationalities and 
actions while hindering others (Fuenfschilling \& Truffer, 2014). Innovations might be rejected because they do not fit with existing industry structures or decision-making processes (Smith \& Raven, 2012). Socio-technical transitions are about changes in regimes, and they require both strong alternatives in niches and favourable openings in regime-selection environments via dynamics and tensions within and between regimes as well as due to landscape pressure (Smith et al., 2010).

Niche is defined as a protective space for path-breaking innovations which fail to successfully compete within the selection environments of incumbent socio-technical regimes. In this paper, the decentralised circular system is a potentially path-breaking innovation which the public sector is expected to protect in the context of urban land-use planning (Figure 1). In niches, innovations can become competitive within unchanged selection environments (fit and conform) or when mainstream selection environments change in a way favourable to them (stretch-and-transform). When an innovation is developed to fit and conform to an existing regime-selection environment, its sustainability is often compromised (Smith \& Raven, 2012).

\subsection{Decentralised circular system}

The authors have developed a decentralised circular system that consists of an alternative sanitation system (Maurer, Bufardi, Tilley, Zurbrügg, \& Truffer, 2012) (source-separating and urine-diverting low-water toilets); a small-scale biogas plant to treat feces or black water, biowaste, energy crops and plant residues; and the local utilisation of nutrients and gas (Figure 2). In source-separating sanitation, black water (from a toilet) is collected separately from other domestic wastewater. Furthermore, low-water (dry or vacuum) toilets enable concentrations of black water and, subsequently, direct treatment in an anaerobic digester. Urine contains most of the nutrients but has low energy potential, and it may be diverted from black water using a urine-diverting toilet. In the decentralised circular system, nutrients recovered from urine and anaerobic digestion feedstock are used in local scenery fields to cultivate energy crops and/or in nearby greenhouse cultivation. After upgrading, biogas can be used locally, e.g., in household gas cookers, as vehicle fuel, or it can be injected into a gas grid. Grey water is treated either on site or directed to centralised treatment; it can also be re-used, e.g., in greenhouse irrigation or as flush-water, if it fulfils quality criteria. In Finland, fields are not typically irrigated; but when global applications are considered, irrigation methods (Valipour, 2012) have greater importance. 

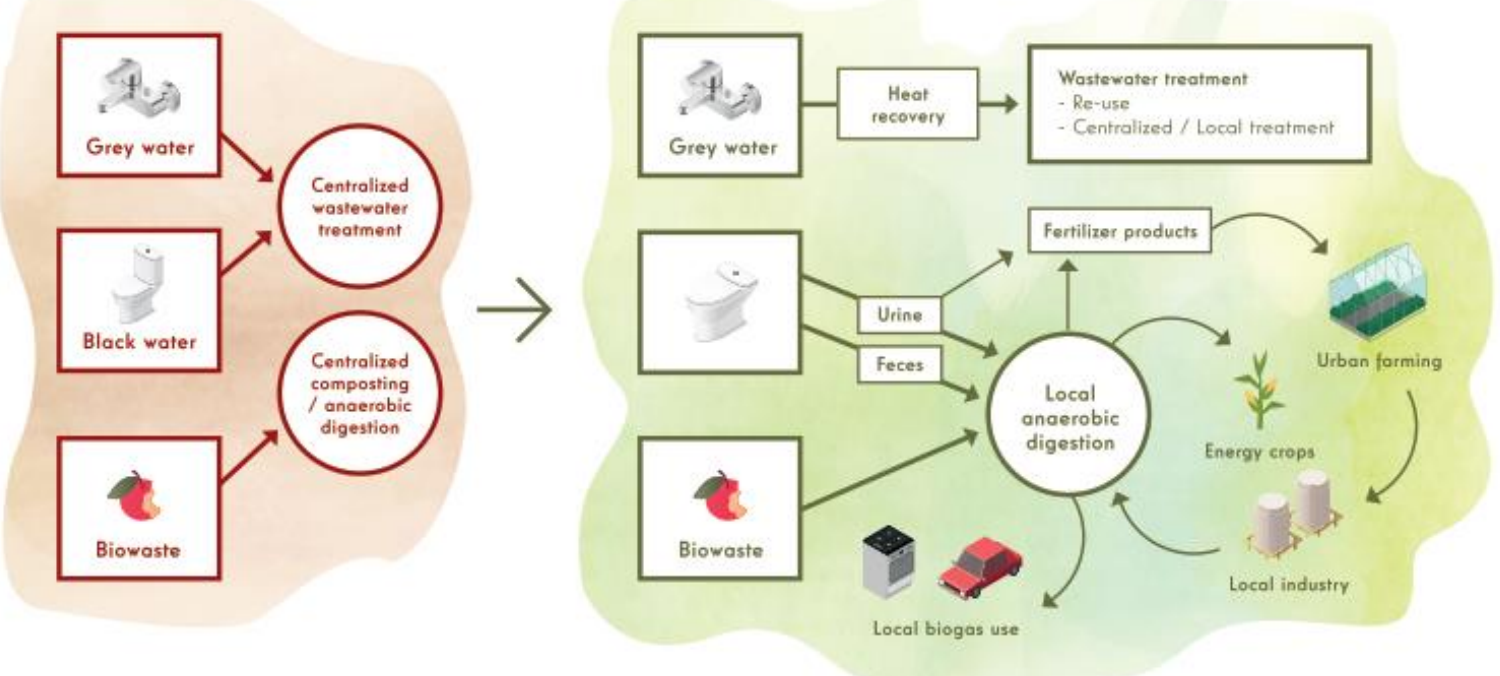

Figure 2. The transition from a conventional sanitation system to a decentralised circular system, which consists of source-separating toilets; a small-scale AD plant to treat local waste streams; and local utilisation of end products. (Figure: CLIC Innovation)

\subsection{Case city of Tampere, Finland}

Finland is a Nordic country with approximately 5 million inhabitants, a low population density and abundant freshwater resources. In this study, the authors focused on the City of Tampere, which is one of the few growing urban areas (226,000 inhabitants) in the country (Figure 3$)$. To position the decentralised circular system, current regimes in the case area need to be understood. Currently, Tampere and its neighbouring communities rely on centralised wastewater treatment and municipal solid waste incineration. Biogas is an emerging technology for biowaste and sludge treatment. However, composting is a prevailing technology, and incineration is a competing alternative in sludge treatment. The central water supply and sewage system covers 85 to 96 percent of households in the Tampere region's communities (Meriluoto, Vinnari, Huttunen, \& Salonsaari, 2010). Mixed solid waste collection covers all of the households, whereas separate biowaste collection covers only urban centres. In sparsely populated areas, decentralised and household-scale solutions for the water supply (water cooperatives and wells), biowaste treatment (composting), and sanitation (small-scale treatment of wastewater or dry toilets) are in use. The studied decentralised circular system challenges ongoing development, which relies on centralisation. 


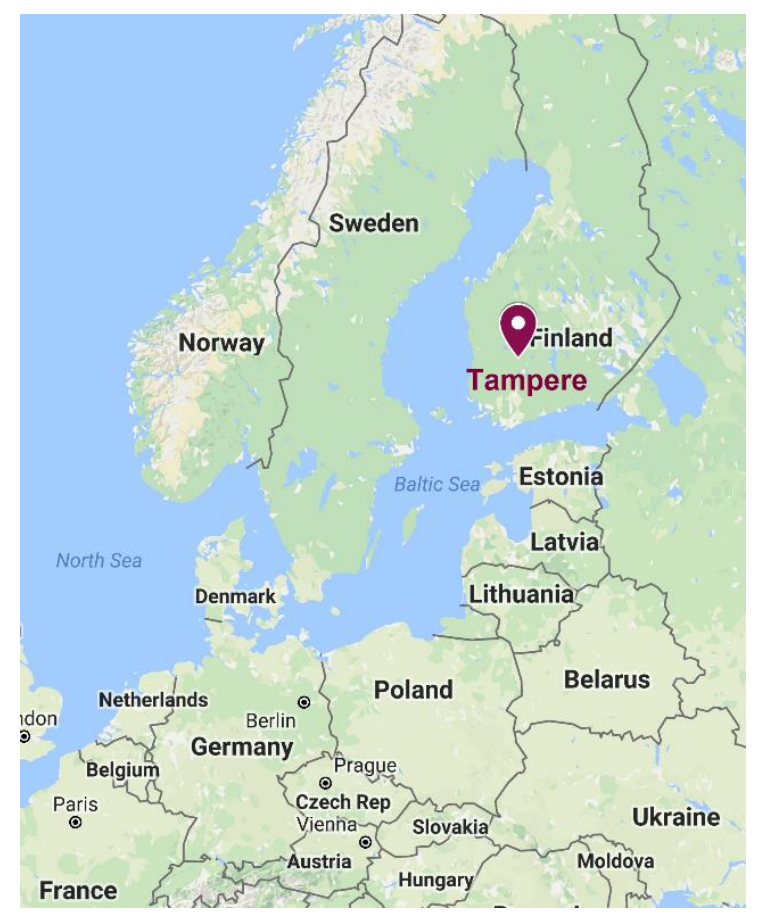

Figure 3. The case city of this study, Tampere, located in southern Finland. (Map data: Google 2016)

\subsection{Data acquisition and analysis}

Seventeen experts were interviewed face-to-face during autumn 2015 (Table 1). We looked for experts who were (or could be) involved in land-use planning in Tampere, and who could complement the views of different actors to the complexity of local applications. First, interviewees were selected based on a research steering group's expertise. The steering group consisted of representatives of the Sustainable Bioenergy Solutions for Tomorrow (BEST) research programme. Further interviewees were chosen based on gaps observed during earlier interviews and recommendations from interviewees (snowballing method). The current regime was covered by six city employees involved in land-use planning, representatives of municipal undertakings that run waste and sanitation services, a property developer from a construction company, and consultants who deal with land-use planning-related tasks outsourced by the city. When selecting new service/technology providers needed in niche implementation, focus was placed on alternative sanitation systems and biogas production. Most of the experts worked in R\&D-oriented positions in their organisations.

Table 1. The interviewees, their organisations, and their expertise

\begin{tabular}{lll} 
Interviewee & Organisation & Expertise \\
\hline 1 & City of Tampere & Water management \\
\hline 2 & City of Tampere & Impact assessment and stakeholder participation \\
\hline 3 & City of Tampere & New residential area management (Vuores project) \\
\hline 4 & City of Tampere & New residential area management (Vuores project) \\
\hline 5 & City of Tampere & Energy and climate \\
\hline 6 & City of Akaa & Politician \\
\hline & Municipal & Central wastewater treatment plant under planning \\
& undertaking & \\
\hline
\end{tabular}




\begin{tabular}{lll}
\hline 8 & $\begin{array}{l}\text { Municipal } \\
\text { undertaking }\end{array}$ & Waste R\&D \\
\hline 9 & $\begin{array}{l}\text { Municipal } \\
\text { undertaking }\end{array}$ & Automatic vacuum waste collection system \\
\hline 10 & $\begin{array}{l}\text { Construction } \\
\text { company }\end{array}$ & Construction contracting \\
\hline 11 & Consultant & $\begin{array}{l}\text { Energy and environmental design: calculation, simulation, } \\
\text { ideas, competitions and planning }\end{array}$ \\
\hline 12 & Consultant & Planning of water, sewage and stormwater networks \\
\hline 13 & $\begin{array}{l}\text { Technology/service } \\
\text { provider }\end{array}$ & $\begin{array}{l}\text { Waste/wastewater collection and treatment systems and } \\
\text { marine sector product development }\end{array}$ \\
\hline 14 & $\begin{array}{l}\text { Technology/service } \\
\text { provider }\end{array}$ & Biogas business \\
\hline 15 & $\begin{array}{l}\text { Technology/service } \\
\text { provider }\end{array}$ & $\begin{array}{l}\text { Participating in city planning/development and offering } \\
\text { gas solutions }\end{array}$ \\
\hline 16 & $\begin{array}{l}\text { Technology/service } \\
\text { provider }\end{array}$ & Gas R\&D \\
\hline 17 & $\begin{array}{l}\text { Technology/service } \\
\text { provider }\end{array}$ & Biogas business development \\
&
\end{tabular}

Semi-structured interviews included the following themes: experience with new residential area development, the actor's role in land-use planning, the actor's potential role if the decentralised circular system is implemented, and narratives of successful/unsuccessful innovations. During each interview, the decentralised circular system (Figure 2) was presented with ppt-slides, and experts were asked to comment on interview themes and other issues freely during the presentation. Presentations often led to lively discussions in which interviewees asked more questions, offered improvement ideas, and commented/criticised the decentralised circular system. The interviews lasted 30-120 minutes and were voice-recorded and transcribed. In addition, all interviewees and steering-group members were invited to a workshop in which drivers, barriers and enablers of decentralised circular system implementation (interview results) were discussed and developed. Workshop participants selected the key issues that should be emphasised in this study and recommended further research. Considering the two-stage research method and the diverse professional and institutional backgrounds of the interviewees, the authors concluded that the 17 selected experts were sufficient to provide the answers to the research questions.

In directed content analysis (Hsieh \& Shannon, 2005), drivers, barriers and enablers for alternative system implementation were sought. Drivers and barriers are multi-dimensional, causing (Geels, 2012) or hindering (Zhao, Chang, \& Chen, 2016) socio-technical transition, respectively. In this paper, drivers refer to landscape-level signals (Tenggren, Wangel, Nilsson, \& Nykvist, 2016) and trends which enhance the decentralised circular system's potential. Barriers represent obstacles to the deployment of the alternative system (Quezada et al., 2016) and exist at each of the multiple levels (Zhao et al., 2016). Among various terms, the authors adopted enabler, defined as a requisite condition for supporting the adoption of an alternative system (Quezada et al., 2016). It was found useful to describe conditions that are not (yet) stabilised but which can develop to support or hinder the alternative system. 


\section{Interview results}

In this section, drivers, barriers and enablers which the decentralised circular system face in the context of urban land-use planning are presented. Themes raised in the interviews were divided into seven categories: interactive land-use planning and the role of actors, information production and sharing, environmental values, technical development and cost-efficiency, operations model, suitable area, and local benefits. The results were further organised under two headlines derived from the research questions: urban land-use planning that enables transition (regime level) and characteristics of potential alternative concepts (niche level).

\subsection{Urban land-use planning that enables transition}

\subsubsection{Interactive land-use planning and the role of actors}

Interviewees described the City of Tampere to be in a state of change from conventional planning practices towards more open and interactive methods, whereby different experts have become involved in the early stages via methods such as competition, alliances and collaborative urban planning:

'Our project aims to enhance new practices. When the city puts effort into something, other actors also give their input' (City of Tampere).

Heterogeneous groups were said to produce more fruitful plans. On the other hand, discontinuity and lack of resources for R\&D in city organisation, lack of cooperation between competing companies, subjective interests versus overall benefits, dominant individuals or organisations, and engagement by actors in a prolonged process were listed as challenges facing interactive land-use planning. The implementation of innovative plans is also challenging:

In new area planning, there are so many things that it is easy to choose an old system here. A new system invites people to complain and slow down the process. Sometimes we study new ideas, but they are not implemented because residents or other city officers are against them' (Consultant).

According to the experts, a project owner who has the will and capability to finish the project is needed to implement innovations and manage context. The project owner should also be easy to contact when new ideas are brought in. When this study was carried out, a new residential area, Vuores, was under construction in Tampere. The Vuores project, which is an interdisciplinary management unit responsible for planning and construction in the area, was mentioned as an example of successful project ownership. In addition, collaborative urban planning and automatic vacuum waste collection were introduced in Vuores. In the case of vacuum waste collection, representatives of municipal undertakings acted as pragmatic system builders and have been recognised as essential in translating niche practices into forms agreeable to regime actors (Smith, 2007). These representatives benchmarked international implementations, sought suitable technology providers, created new financing models, and communicated actively with the City of Tampere.

Current operators were said to have established roles in land-use planning, so new areas were planned based very much on old systems. This finding supports the claim that infrastructure 
planning has a narrow perspective which fails to take into account uncertain context conditions, value considerations, and available technological alternatives (Störmer et al., 2009). Current operators defended the reliability and effectiveness of current systems, but they also seemed open to new, well-reasoned roles and solutions. A barrier to renewing practices recognised by many experts is that operators get into land-use planning too late. Some new technology/service providers were also interested in participating and lobbying for their solutions, but their role would be unclear, and they face the same problem of getting involved too late. Conflicting interests encountered in land-use planning are described below:

'Actors think of their own benefit, not an overall picture; for example, HSY uses biogas in its own CHP plant, even though (it's) better for the whole system to use it as gas somewhere else' (Service/technology provider).

Resident participation raised two kinds of thoughts in the interviews. On the one hand, citizens are experts in residential area development, participation increases knowledge and acceptability, and heterogeneous groups are creative. On the other hand, participation can be frustrating if people resist just on principle. Also, Peltonen \& Sairinen (2010) mentioned that although urban planning has become more participatory, it is often conducted 'by the book' to fulfil legal requirements. More real interaction is needed to manage conflicts and build consensus between stakeholders. In the case of new residential areas, it was unclear who should represent future residents. Politicians and focus/discussion groups were mentioned. It was also considered difficult to forecast who would move to a new area, and therefore generalisable solutions and compromises for different people were preferred. However, this can be a barrier to alternative-concept implementation.

Some experts representing the City of Tampere and technology/service providers demanded stricter city control over urban planning. It was debated whether owner direction works in the case of municipal undertakings that operate infrastructures, as well as how to guarantee planning quality when land-use planning is outsourced to consultants. Once development targets are on paper, they become useful tools in land-use planning when there are conflicting interests. For example, in stormwater management, renewal of water management and land use and building legislation in 2014 and a recent city stormwater programme have facilitated the implementation of local, decentralised treatment methods.

\subsubsection{Information production and sharing}

To implement new systems and break path-dependence (Matthews, Lo, \& Byrne, 2015), political willpower among decision makers (politicians and officers) needs to be cultivated early on. In addition to cost and environmental data, it was suggested that a wide set of viewpoints and potential impacts be presented for decision makers, who can then make a decision based on their values. Information breaks within city organisation were mentioned as a barrier for new system implementation, and decision makers' involvement in R\&D projects and pilots was seen as a solution for discontinuous information flow.

Besides decision makers, other stakeholders also need useful information early on. A few examples of interest-group demands were mentioned in interviews: 
'Residents need to know, in time, additional costs that they need to pay. In Vuores, there was discussion that residents didn't fully understand what they needed to pay for vacuum collection and other services in the area' (City of Akaa).

'We help customers in the permit process by producing information for officer use. This could be a role also in residential area cases' (Service/technology provider).

'Supervision of construction is not always up to date regarding new solutions' (Consultant).

Using professionals in communications was recommended for the City of Tampere. Expertise is needed in presenting the information so that it serves different target groups. Presenting information in public was considered important because it prevents rumours and affects the reputation and acceptability of the system.

\subsubsection{Environmental values}

According to city representatives, global megatrends are utilised in city strategies; but as a practical matter, they are integrated slowly. City strategies are broad, and the decentralised circular system was assessed to fit with these strategies. City of Tampere actors expressed interest in implementing green solutions, but it is difficult to know what to enable. Besides city actors, other actors appreciate the environment as well and look forward to new green solutions:

'Biogas has strategic importance/potential. In recent organisational change, biogas was separated into a new business unit. Gasum is working on a carbon-neutral roadmap, and biogas has a significant role in the future. Small-scale solutions have not been implemented, but they are a trend' (Service/technology provider).

'Depends on the actor. Some companies that build and manage large building masses are ready to invest a lot for a new solution if it can be used in marketing. Other actors just talk about environmental values, but don't invest a penny' (Consultant).

In the interviews, environmental values were often described in relation to economics. On the one hand, environmental issues were seen as an expensive add-on. On the other hand, a better environment was seen as a way to boost the image of a residential area. Trends were said to be moving from economy-driven urban planning towards situations in which environmental values have greater importance. In the citations below, the economy-environment conflict and the roles of different actors are expressed:

'For city planners, it is easy to promote new solutions, but construction companies bring in economical facts. Salespeople sell anything, and some construction companies avoid everything new. The right way is somewhere in between' (Construction company).

'If a pilot is implemented in Finland, companies will get a reference to other countries where urbanisation is rapid and hygienic problems severe' (City of Tampere).

Besides cost, another issue competing with environmental values is acceptability. The decentralised circular system was observed to include many risks and aspects that people may oppose. Such issues can be used to complain about and/or slow down new area building. Actual reasons to resist can include either the risks in question or something else. Risks noticed in interviews include biogas plant/handling inside a residential area, land use, odours and micro aerosols, urine-separation functioning, vacuum-toilet noise, the risk of nutrients leaking into water bodies, and the acceptability of waste-derived fertilisers. Respondents offered solutions on how to improve 
acceptability: Actors should be prepared for complaints against a plan and be ready to respond. Furthermore, the system should not be too demanding for users. The defensive solutions offered indicate that early value mapping of key stakeholders in urban land-use planning (Vierikko \& Niemelä, 2016) has not yet been assimilated by all actors in a regime.

\subsection{Characteristics of potential alternative concepts}

\subsubsection{Technical development and cost-efficiency}

Experts concluded that there are plenty of technical solutions for the decentralised circular system's implementation, but cost-efficiency is a big challenge. Small-scale solutions are often difficult to make profitable. However, decentralisation and renewable energy are seen as likely future paths in the energy sector, and companies are currently developing technology for small and hybrid systems. In the sanitation sector, decentralised solutions are widely used in sparsely populated areas; but in urban environments, they are marginal, and service/technology providers do not necessarily see business potential in cities. However, in planning tables, alternative systems such as vacuum toilets are already being discussed. The importance of infra-development and a key question challenging decentralised circular systems are presented below:

'A large share of a city's financial resources is used for infra, and water infra works well.
Therefore, changes in it need to be reasoned well' (City of Tampere).

'If energy production is marginal, is it economical to build more expensive systems, and what is its repayment period?' (City of Akaa)

The importance of the overall picture in system-cost calculations was highlighted. Centralisation benefits can decrease when some areas do not join the system. On the other hand, avoiding long pipes and pumps and lightly treating grey waters may decrease the overall price of the decentralised circular system. Also, incentives and output (energy, nutrients) prices were said to affect the profitability of the system. The time perspective needs to be considered as well: A bigger investment is acceptable if operating costs are low. Sometimes, sufficient population and density are needed to make the system feasible. On the other hand, light, nature-based solutions can be suitable and economical, especially in less-dense areas where land-use competition is not that intense. Land- or space-use competition also occurs when technical systems are placed in buildings and under streets. The more space needed for technology, the less $\mathrm{m}^{2}$ to sell.

Based on the interviews, one driver for technology breakthroughs is maturity. In the decentralised circular system, one barrier can be an immature stage of the system as a whole or parts of it. New solution testing in pilot projects was also highlighted in many interviews. Pilots were said to enable the sharing of responsibility and risks, generate information, give companies references, facilitate exports, improve technology, test systems and change legislation. Funding for pilots was demanded from R\&D financial instruments. However, upscaling was considered uncertain. It was said that pilot systems are not easily distributed to regular building projects, and that failed pilots spoil a system's reputation for a long time. Improvements for pilot upscaling were subsequently suggested. Failed projects should also be analysed, and the city organisation should become a learning organisation where pilots are discussed regularly with directors. 


\subsubsection{Operations model}

A new system provides space for new roles and actors, and the importance of finding good partners for each part of the system was highlighted in the interviews and especially in the workshop. According to a potential service/technology provider, urban resource-flow analysis and opening value chains - what kinds of benefits does the industrial ecosystem (Figure 2) create for different actors? - are needed to develop new operation and business models. An increasing number of actors creates a challenge. According to a current operator, cooperation, responsibilities, the fitting of pipes under streets, and maintenance work are already difficult with 'too many operators' (water, street, central heating, electricity and telephone operators).

When new companies offering solutions were considered, having a sufficient competition was deemed important. According to a construction company, it is risky to bind a property/area to such a system, in which an operator is in a monopoly position for a long time. Resident-run operations generated doubtful comments. Experiences from small waterworks have shown that a professional operator has better resources for continuity, long-term economics and investments. Some respondents could perceive residents taking on a bigger role. According to a technology/service provider, an biogas plant could be distantly monitored, and a resident organisation or energy entrepreneur could do simple tasks on site.

In the case of vacuum-waste collection in Vuores, it was deemed necessary for all houses to be part of the new system. Doing so guaranteed sufficient funding and equal cost burdens for different houses in Vuores. Plot assignment stipulations by the City of Tampere mandated contruction companies to join the new system. In Finland, legislation requires property owners to sign up for municipal waste and wastewater collection or organise wastewater treatment in sparsely populated areas. This requirement was seen as a driver for the decentralised circular system. Furthermore, it was mentioned that in the energy sector, such legislation does not exist, and the City of Tampere does not order homeowners to sign up with any heating utility. According to a City of Tampere representative, for apartment houses in the city centre, district heating is often an easy choice, but single-house builders tend to appreciate privacy and want other options. This mindset can be a barrier to village solutions that involve households joining the studied system.

There are many options for financing the decentralised circular system. In interviews, it was suggested that the city finance part of it, that it be fully paid for by residents, that it should be market-based, or that outside funding should be sought, either from investors or through environmental incentives. When residents take part in financing, they should be treated equally. Money was said to be the best consultant, and solutions could be directed towards new systems (on-site stormwater management) by charging users for using conventional solutions (pipes, containers). The market-based solution was questioned by municipal undertaking representatives because some say there is a lack of market potential around biogas plants; moreover, they claim that there is a risk that business-oriented solutions would fail to take care of health- and environmentalrelated duties in waste and wastewater management.

\subsubsection{Suitable area}

This study was restricted to a new residential area. However, in some interviews, existing areas were seen as potential locations for the decentralised circular system. Alternative solutions were found to be easier to implement in new areas because land-use planning is more straightforward and new 
solutions are easier to accept when they are already in place when people move in. Existing infrastructure both prevents and enables an alternative system:

'In Tampere, there is a gas grid where biogas could be injected. Heat could be fed into a smarter district heating network. On the other hand, the city is kind of a prisoner of existing infra: Strong centralised systems can hinder the development of new concepts' (City of Tampere).

'Until now, the focus has been on solutions where biogas can be upgraded and injected into a grid. That is efficient and enables reaching a large number of customers. Recently, the outside grid world has also been considered; there are also smaller solutions possible' (Service/technology provider).

A municipal undertaking representative said that, so far, the challenge in waste and wastewater management has been to get waste streams together and treated. Centralisation has been driven by health, environment, reliability and economic benefits. Now that there are working centralised systems, launching distributed alternatives was considered challenging. However, in certain locations, decentralised systems were seen as reasonable.

The natural location for the decentralised circular system was agreed to be at the border between the city and the countryside. In Tampere, these kinds of locations are existing villages in Teisko. Far from the city centre, centralised systems such as sewage networks, separated biowaste collection and district heating are often nonexistent or not feasible. Similarly, providing services for a small number of households was regarded as a challenge for the studied system. It was proposed that in such locations, synergies for the decentralised circular system could be sought with agriculture. Local drinking-water sources, which are needed if the aim is to avoid long pipelines, were also mentioned as a challenge. Currently, potential locations have local water sources, but problems with water quality were mentioned. An environmentally profiled new residential area was also considered a potential location for the decentralised circular system. A house fair area was raised as one possibility, where new ideas could be tested and higher costs would be accepted. In general, when an area is more attractive, higher costs and construction requirements are seen as acceptable. If this kind of area is located near the city centre, it was proposed that synergies could be sought with industry (feedstock, energy use and reputation).

In any case, interviewees agreed that the system needs to be adapted to local conditions. Experts concluded that in Tampere, easy locations are already built; and in new areas, geotechnical soil properties, varying elevations and soil contamination affect options for treating wastewater and using local nutrients. In densely built areas near the city, there is also land-use competition, and land requirements in the local system were found to be challenging to meet. Unlike conventional gravitation sewage, vacuum sewage works uphill, which was evaluated as a driver in some locations.

It was assumed that in the beginning, average people would not move to a pilot area. If a system differs from a norm, it requires a certain commitment, and residents need to be like-minded. A city representative mentioned that groups that want to establish eco-villages are seeking the right municipalities. This kind of activity was seen as a good starting point for the pilot effort. A suitable area, outside the reach of centralised infrastructures and the environmentalist milieu, whose members accept higher costs or lower performance when an innovation performs better environmentally or is more socially just, are examples of protective space (Smith \& Raven, 2012). 


\subsubsection{Local benefits}

Consultants and a construction company said that circuits, where resources are used locally and benefit producers, should be made visible. Such benefits can be environmental, social and/or economical: More attractive areas with lighter traffic, lower heating costs in apartments or public buildings, an energy supply in case of emergencies, and local vehicle fuelling stations or gas for cooking were mentioned. Below, experts reflect on the best ways to use biogas locally:

'Part of private house heating is not that good because there needs to be something else also' (Consultant).

'The most efficient way to use gas is to use it as gas somewhere where it brings additional value; for example, the food industry' (Service/technology provider).

'A local transportation gas station could work if in traffic node. It motivates new car introduction' (Municipal undertaking).

Local benefits are shaped by two issues: the overall effects of the system and the motivation to invest. A representative of a municipal undertaking concluded that in remote locations and at small scales, outputs (energy and nutrients) are likely to be more feasibly used locally than if they were transferred to central systems. A decentralised circular system was seen as having the potential to overcome nutrient recycling barriers because the nutrient source is known and restricted to households. However, respondents were not sure about regulations; and this, together with difficulties finding an expert to comment on legislation in the interviews, indicates that legislation is an unclear precondition (Hukari et al., 2016).

Somewhat higher home-construction costs, which would be caused by the new system, were found to be acceptable if local benefits are made apparent. In attractive areas, higher prices are seen as acceptable but also risky should houses not get built or building proceeds slowly. One construction company representative estimated that in Vuores, the investment price was approximately 10 percent higher due to the additional systems required, and that this was close to the limit. Construction company representatives and consultants said that if benefit information, including potential savings, is available early, it can be used in marketing the area; moreover, investors, home buyers and tenants can use the information in their decision making.

The results are summarised in Table 2 .

Table 2. Summary of the drivers, barriers and enablers for the implementation of the decentralised circular system in Tampere.

Drivers - - The City of Tampere has the goal of moving towards open and interactive urban planning methods, which would allow new actors and ideas to be included in planning tables.

- $\quad$ Actors promote green values.

- Branding new neighbourhoods to stand out from the rest is a trend in urban planning, and this can be promoted by new environmental solutions.

Barriers - Information breaks within the network of actors prevent the progress of alternative solutions.

- Human health-related pressures to find new, immediate solutions to sanitation, irrigation, etc., are lacking in urban areas in Finland. The city 
plays an enabling role in urban planning, but for municipal officials and politicians, it is unclear which technologies/solutions should be enabled.

- Economics and acceptability override environmental values.

- Current operators dominate and must remain in their old roles in planning.

- Actors get into land-use planning too late, and the roles of new actors are unclear.

- The cost-efficiency of new and small-scale solutions is a challenge.

- Pilot upscaling is not systematic.

- Existing infra (e.g., long pipelines) may reduce system benefits.

Enablers - The project owner is needed to communicate between niche and regime levels.

- Strengthening city guidance in infrastructure development regarding (environmental) policy aims and the contributions of residents and stakeholders to urban planning may enhance creativity, shared value creation and acceptability.

- Communication professionals can help with translations within the network of actors.

- Decision makers' involvement in R\&D projects and pilots increases political willpower and information and promotes implementation.

- Suitable locations: City outskirts, far away from central plants or a dense urban area with an environmental profile, or a challenging profile for gravitation sewage.

- Existing infra (e.g., gas grids) may support the system in certain locations.

- A visible loop (e.g., nutrients/energy) and local benefits increase attractiveness.

- Increased knowledge on impacts and a comparison to the dominant system in each case are needed to support decision making.

- Technology for the decentralised circular system is available.

- Technology needs to be mature enough.

- Competent partners for each part of the industrial ecosystem are needed.

- Operations and financing solutions require open thinking.

- Making the city a learning organisation by utilising pilots, failed projects etc.

\section{Discussion}

\subsection{How to get from here to there}

When looked at from a multi-level perspective, urban land-use planning belongs to regimes, which have to change in order to enable socio-technical transitions (Smith et al., 2010). However, the decentralised circular system belongs to niches, which should develop so they can compete in regime selection environments or, preferably, change those environments (Smith \& Raven, 2012). The authors assume that strengthening the enablers identified in this study and overcoming barriers, may facilitate a socio-technical transition towards more sustainable urban infrastructures in Tampere. In Figure 4, improvement suggestions are arranged according to MLP. 


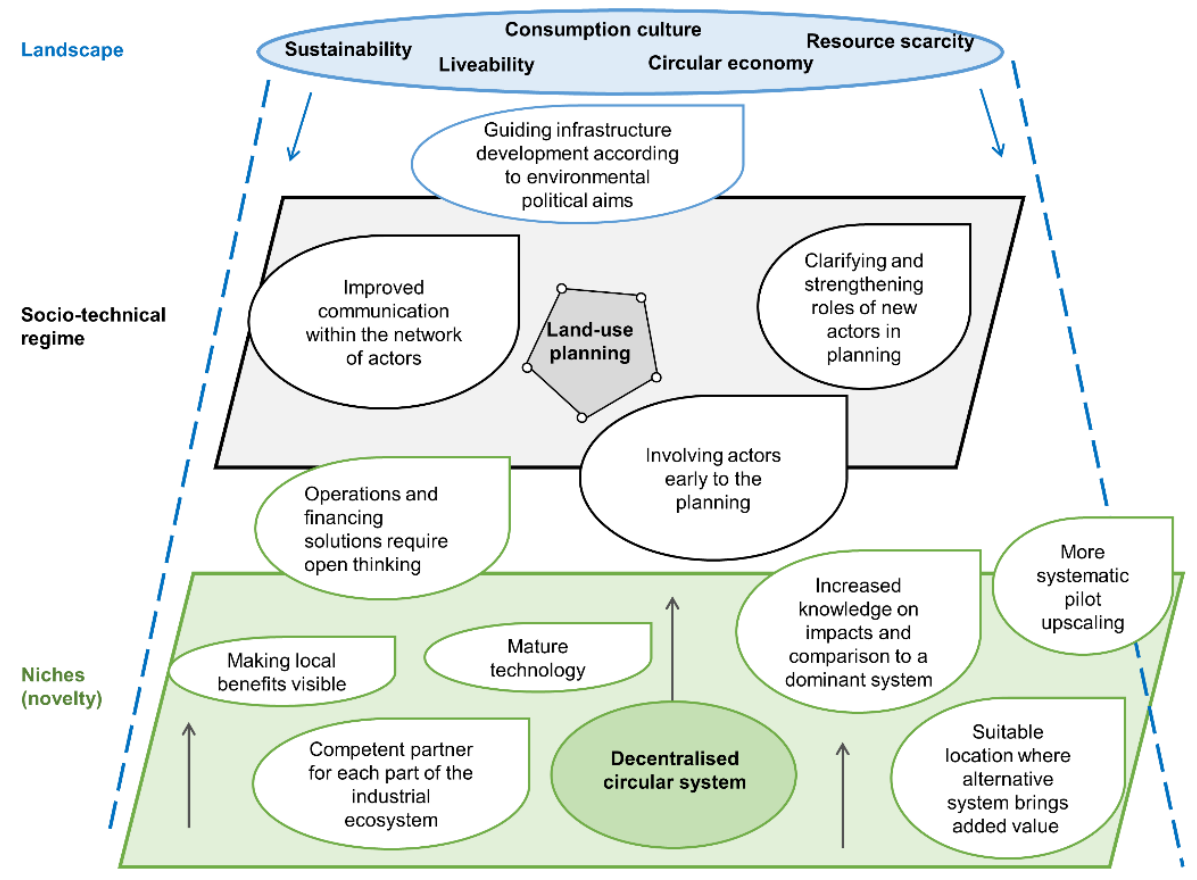

Figure 4. Suggestions for improving conditions that support a circular system neighbourhood on multiple levels.

Starting at the landscape level, a sustainability transition could be facilitated by bringing values into practice more effectively. Environmental values and alternative solutions tend to get lost in multistage urban land-use planning, procurement and outsourced operations. Despite its enabling role in land-use planning, the City of Tampere should remain in control and guide infrastructure sectors according to (environmental) political aims. At the regime level, the crucial challenge of urban landuse planning is to accept new actors (operators, potential technology/service providers, residents/civil society) and alternative solutions more systematically and honestly without losing the benefits of currently functioning infrastructures, which should instead be improved. In terms of participation, the formation of issues is more important than conducting the procedure 'by the book' (Leino \& Laine, 2012). As technological development is accelerating, the public sector needs to improve its ability to react, learn and adapt (Ribeiro \& Zamparutti, 2015). At the niche level, the success of the decentralised circular system and the actions supporting it depend on local conditions. Improving the feasibility of such an industrial ecosystem requires open thinking, competent partners, mature technology and suitable locations. Visible local benefits can make the system more attractive and acceptable.

\subsection{Feasibility of the decentralised circular system}

Facilitating socio-technical transition is discussed above, but could the decentralised circular system become a part of infrastructure in Tampere? The authors assume that it could balance resource cycles, enhance renewable energy production, reduce infrastructure costs, and support the socioeconomic development of local businesses and societies in certain locations. In addition, ongoing $R \& D$ of energy technologies and nutrient recycling may improve the cost-efficiency of the system. However, this paper did not focus on these effects. 
Critically speaking, some of the results call into question the ability of the decentralised circular system to improve sustainability and liveability. First, a high-profile neighbourhood in a pristine area seems to be a suitable location for the system because residents there are ready to pay and there is a lack of infrastructure (e.g., pipelines). However, construction on greenfield land is not the desired direction of urban development, and a liveable area should be accessible to a wider socio-economic group. Therefore, cost-efficiency, cost avoidance and local benefits should be sought from locations where other aspects of sustainability are not compromised. Second, the technical maturity of the decentralised circular system is doubtful. When components of several novel solutions (including alternative sanitation systems, small-scale anaerobic digestion and urban farming) are combined, technical and operational challenges cannot be avoided. In addition, the acceptability of the studied system is uncertain. Current urban waste/water management is based on the 'flush and forget' principle, and local treatment possibly requiring resident maintenance needs to be thought out carefully in a participatory planning process. Finally, negative environmental effects need to be considered if the decentralised circular system were to be implemented. e.g., a lifecycle assessment from Sweden (Spångberg, Tidåker, \& Jönsson, 2014) showed that source-separating sanitation and nutrient recycling improved energy efficiency and decreased global-warming potential, but increased the potential for eutrophication and acidification when compared to advanced wastewater treatment plants and artificial fertilisers.

By comparison, in Australia, where extreme weather conditions have pushed reforms forward, the urban water sector is in the early stages of a multi-decade shift from centralisation to partial decentralisation based on local conditions (Quezada et al., 2016). Transition in the Australian water sector is described as a competition between 'water-sensitive logic' and 'water-market logic', which are challenging the current 'hydraulic logic'. Hydraulic logic is characterised by public authorities and technical expertise, water-market logic by private firms and economic expertise, and water-sensitive logic by social movements and decentralised water-recycling technologies (Fuenfschilling \& Truffer, 2014). Urban infrastructures may develop similar routes in Finland. However, any transition in Finland will likely be shaped by local characteristics, such as abundant water and forest resources, a northern climate, the welfare state, autonomous municipalities, long distances and a sparse population. Forecasting forms of socio-technical transition is difficult, or as (Bell, 2015) put it: 'Alternative technologies and discourses are emerging in urban water infrastructure, but are far from unified in the ideologies they stabilise.'

\subsection{Conclusions and further research}

This study focused on one niche-level innovation and how it could unbalance incumbent regimes in Tampere, Finland. However, the results elicit still wider questions about socio-technical transition in infrastructure sectors. Any niche-level innovation would face a similar struggle getting into urban land-use planning and actually being implemented. The main improvement suggestions, such as early involvement of actors, improved communications, and more systematic pilot upscaling, may be applied to any city; whereas some drivers, barriers and enablers, e.g., dominant current operators and acceptability, depend more on local conditions such as urban planning practices and suitable technologies. Further research should include the role of residents in the sustainability transition within infrastructure sectors, houses as an interface for infrastructure systems, information flow in land-use planning, impact assessment and pilot upscaling. 


\section{Acknowledgements}

The authors would like to thank all of the interview and workshop participants for their time and thoughtful comments; Mari Tuomaala (Gasum) and Marja Englund (Fortum) for their inspiration initiating and guidance of the research project; Principal Scientist Maria Åkerman (VTT); and anonymous reviewers for their many constructive insights and suggestions.

Funding: This work was supported by the Finnish Funding Agency for Technology and Innovation, Tekes [grant number 48/31/2013]; and author XX was supported by the Academy of Finland [grant number 289691]. 


\section{References}

Alanne, K., \& Saari, A. (2006). Distributed energy generation and sustainable development. Renewable and Sustainable Energy Reviews, 10(6), 539-558. doi:http://dx.doi.org/10.1016/j.rser.2004.11.004

Aubain, P., Gazzo, A., Le Moux, J., Mugnier, E., Brunet, H., \& Landrea, B. (2002). Disposal and recycling routes for sewage sludge - Synthesis report. European Commission. URL: http://ec.europa.eu/environment/archives/waste/sludge/pdf/synthesisreport020222.pdf last accessed 20.12.2016

Bell, S. (2015). Renegotiating urban water. Progress in Planning, 96, 1-28. doi:http://dx.doi.org/10.1016/j.progress.2013.09.001

Brentrup, F., \& Palliére, C. (2008). GHG emissions and energy efficiency in European nitrogen fertiliser production and use. (No. 639). International Fertiliser Society.

Cordell, D., Drangert, J., \& White, S. (2009). The story of phosphorus: Global food security and food for thought. Global Environmental Change, 19(2), 292-305.

doi:10.1016/j.gloenvcha.2008.10.009

de Haan, F. J., Ferguson, B. C., Adamowicz, R. C., Johnstone, P., Brown, R. R., \& Wong, T. H. F. (2014). The needs of society: A new understanding of transitions, sustainability and liveability. Technological Forecasting and Social Change, 85, 121-132. doi:http://dx.doi.org/10.1016/j.techfore.2013.09.005

Edwards, J., Othman, M., \& Burn, S. (2015). A review of policy drivers and barriers for the use of anaerobic digestion in Europe, the United States and Australia. Renewable and Sustainable Energy Reviews, 52, 815-828. doi:http://dx.doi.org/10.1016/i.rser.2015.07.112 
Ferrer, A. L. C., Thomé, A. M. T., \& Scavarda, A. J. (2016). Sustainable urban infrastructure: A review. Resources, Conservation and Recycling, doi:http://dx.doi.org/10.1016/i.resconrec.2016.07.017

Finnish Parliament. (1999). Land Use and Building Act 132/1999.

http://www.finlex.fi/fi/laki/kaannokset/1999/en19990132.pdf last accessed 20.12.2016

Fuenfschilling, L., \& Truffer, B. (2014). The structuration of socio-technical regimes-Conceptual foundations from institutional theory. Research Policy, 43(4), 772-791.

doi:http://dx.doi.org/10.1016/i.respol.2013.10.010

Geels, F. W. (2010). Ontologies, socio-technical transitions (to sustainability), and the multi-level perspective. Research Policy, 39(4), 495-510.

doi:http://dx.doi.org/10.1016/i.respol.2010.01.022

Geels, F. W. (2012). A socio-technical analysis of low-carbon transitions: Introducing the multi-level perspective into transport studies. Journal of Transport Geography, 24, 471-482. doi:http://dx.doi.org/10.1016/j.jtrangeo.2012.01.021

Hirvonen-Kantola, S., \& Mäntysalo, R. (2014). The recent development of the Finnish planning system: The city of Vantaa as an executor, fighter and independent actor. In M. Reimer, P. Getimis \& H. H. Blotevogel (Eds.), Spatial planning systems and practices in europe: $A$ comparative perspective on continuity and changes (pp. 42-60). London: Routledge. doi:10.4324/9781315852577

Horizon 2020 sections. European Commission. URL:

https://ec.europa.eu/programmes/horizon2020/en/h2020-sections last accessed 20.12.2016

Hsieh, H., \& Shannon, S. E. (2005). Three approaches to qualitative content analysis. Qualitative Health Research, 15(9), 1277-1288. doi:10.1177/1049732305276687 
Hukari, S., Hermann, L., \& Nättorp, A. (2016). From wastewater to fertilisers--technical overview and critical review of European legislation governing phosphorus recycling. The Science of the Total Environment, 542(Pt B), 1127-1135. doi:10.1016/j.scitotenv.2015.09.064

Junnila, S., Niiranen, I., Majamaa, W., \& Kuronen, M. (2010). Public-private-people partnership as a way to reduce carbon dioxide emissions from residential development. International Journal of Strategic Property Management, 14(3), 200-216. doi:10.3846/ijspm.2010.15

Leino, H., \& Laine, M. (2012). Do matters of concern matter? bringing issues back to participation. Planning Theory, 11(1), 89-103. doi:10.1177/1473095211417595

Malekpour, S., Brown, R. R., \& de Haan, F. J. (2015). Strategic planning of urban infrastructure for environmental sustainability: Understanding the past to intervene for the future. Cities, 46, 6775. doi:10.1016/j.cities.2015.05.003

Manfredi, S., \& Pant, R. (2011). Supporting environmentally sound decisions for bio-waste management A practical guide to life cycle thinking (LCT) and life cycle assessment (LCA). (No. EUR 24917 EN). European Commission Joint Research Centre Institute for Environment and Sustainability. doi:10.2788/53942

Matthews, T., Lo, A. Y., \& Byrne, J. A. (2015). Reconceptualizing green infrastructure for climate change adaptation: Barriers to adoption and drivers for uptake by spatial planners. Landscape and Urban Planning, 138, 155-163. doi:http://dx.doi.org/10.1016/j.landurbplan.2015.02.010

Maurer, M., Bufardi, A., Tilley, E., Zurbrügg, C., \& Truffer, B. (2012). A compatibility-based procedure designed to generate potential sanitation system alternatives. Journal of Environmental Management, 104, 51-61. doi:10.1016/j.jenvman.2012.03.023 
Meers, E. (2016). How to improve the agronomic use of recycled nutrients ( $N$ and $P$ ) from livestock manure and other organic sources? starting paper. (No. 16). EIP-AGRI Focus Group. URL: https://ec.europa.eu/eip/agriculture/sites/agri-eip/files/eipagri_focus_group_nutrient_recycling_starting_paper_2016_en.pdf last accessed 20.12.2016

Meriluoto, J., Vinnari, E., Huttunen, M., \& Salonsaari, H. (2010). Selvitys vesihuoltoyhteistyön kehittämisestä Tampereen seudulla. FCG Planeko Ltd. Tampereen kaupunkiseudun kuntayhtymä. URL:

http://www.tampereenseutu.fi/site/assets/files/4358/vesihuolto_kehittminen_loppuraportti_2 _2010.pdf last accessed 20.12.2016

Peltonen, L., \& Sairinen, R. (2010). Integrating impact assessment and conflict management in urban planning: Experiences from Finland. Environmental Impact Assessment Review, 30(5), 328-337. doi:10.1016/j.eiar.2010.04.006

Quezada, G., Walton, A., \& Sharma, A. (2016). Risks and tensions in water industry innovation: Understanding adoption of decentralised water systems from a socio-technical transitions perspective. Journal of Cleaner Production, 113, 263-273.

doi:http://dx.doi.org/10.1016/j.jclepro.2015.11.018

Ribeiro, T., \& Zamparutti, T. (2015). Assessment of global megatrends - an update global megatrend 4: Accelerating technological change. European Environment Agency. URL: http://www.eea.europa.eu/publications/global-megatrends-update-4-accelerating last accessed 20.12.2016

Ruggiero, S., Varho, V., \& Rikkonen, P. (2015). Transition to distributed energy generation in Finland: Prospects and barriers. Energy Policy, 86, 433-443. doi:10.1016/j.enpol.2015.07.024 
Smith, A., \& Raven, R. R. (2012). What is protective space? Reconsidering niches in transitions to sustainability. Research Policy, 41(6), 1025. doi:10.1016/j.respol.2011.12.012

Smith, A. (2007). Translating sustainabilities between green niches and socio-technical regimes. Technology Analysis and Strategic Management, 19(4), 427-450. doi:10.1080/09537320701403334

Smith, A., Voß, J., \& Grin, J. (2010). Innovation studies and sustainability transitions: The allure of the multi-level perspective and its challenges. Research Policy, 39(4), 435-448. doi:10.1016/j.respol.2010.01.023

Sokka, L., Antikainen, R., \& Kauppi, P. (2004). Flows of nitrogen and phosphorus in municipal waste: A substance flow analysis in Finland. Progress in Industrial Ecology--an International Journal, 1(1-3), 165-186.

Spångberg, J. (2014). Recycling plant nutrients from waste and by-products - a life cycle perspective (Doctoral thesis). doi:http://urn.kb.se/resolve?urn=urn:nbn:se:slu:epsilon-e-1787

Spångberg, J., Tidåker, P., \& Jönsson, H. (2014). Environmental impact of recycling nutrients in human excreta to agriculture compared with enhanced wastewater treatment. Science of the Total Environment, 493, 209-219. doi:10.1016/j.scitotenv.2014.05.123

Störmer, E., Truffer, B., Dominguez, D., Gujer, W., Herlyn, A., Hiessl, H., . . Ruef, A. (2009). The exploratory analysis of trade-offs in strategic planning: Lessons from regional infrastructure foresight. Technological Forecasting \& Social Change, 76(9), 1150-1162.

doi:10.1016/j.techfore.2009.07.008 
Tenggren, S., Wangel, J., Nilsson, M., \& Nykvist, B. (2016). Transmission transitions: Barriers, drivers, and institutional governance implications of Nordic transmission grid development. Energy Research \& Social Science, 19, 148-157. doi:http://dx.doi.org/10.1016/j.erss.2016.06.004

Tervahauta, T. H., Hoang, T., Hernández, L., Zeeman, G., \& Buisman, C. J. N. (2013). Prospects of source-separation-based sanitation concepts: A model-based study. Water, 5(3), 1006-1035. doi:10.3390/w5031006

Valipour, M. (2015). Future of agricultural water management in Africa. Archives of Agronomy and Soil Science, 61(7), 907-927. doi:10.1080/03650340.2014.961433

Valipour, M. (2012). Comparison of surface irrigation simulation models: Full hydrodynamic, zero inertia, kinematic wave. Journal of Agricultural Science, 4(12), 68-74. doi:10.5539/jas.v4n12p68

Verbong, G. P. J., \& Geels, F. W. (2010). Exploring sustainability transitions in the electricity sector with socio-technical pathways. Technological Forecasting \& Social Change, 77(8), 1214-1221. doi:10.1016/j.techfore.2010.04.008

Vierikko, K., \& Niemelä, J. (2016). Bottom-up thinking identifying socio-cultural values of ecosystem services in local blue-green infrastructure planning in Helsinki, Finland. Land use Policy, 50, 537547. doi:10.1016/j.landusepol.2015.09.031

Zabaleta, I., \& Rodic-Wiersma, L. (2015). Recovery of essential nutrients from municipal solid waste impact of waste management infrastructure and governance aspects. Waste Management, 44 , 178-187. doi:10.1016/j.wasman.2015.07.033

Zhao, Z., Chang, R., \& Chen, Y. (2016). What hinder the further development of wind power in China? A socio-technical barrier study. Energy Policy, 88, 465-476. doi:http://dx.doi.org/10.1016/j.enpol.2015.11.004 


\section{Vitae}

M.Sc. (Tech. and Admin.) Maarit Särkilahti has professional experience in waste management and teaching environmental engineering. Currently, she is preparing her dissertation at the Tampere University of Technology, Department of Chemistry and Bioengineering. She studies sustainability transition in infrastructure sectors with an interdisciplinary approach.

M.Sc. Viljami Kinnunen is an environmental technology professional with eight years of experience. His fields of expertise include anaerobic digestion and nutrient recycling. Currently, he works as a research and development engineer for Gasum Ltd, Finland. He regularly teaches in courses and seminars organised by universities and other organisations.

Dr. Riitta Kettunen is a professional engineer and scientist with 25 years of experience in water and environmental engineering and management. Her areas of expertise include drinking water and wastewater treatment, treatment of biosolids, and nutrient recycling in urban areas and industry. Currently, she works as a water production manager and is a member of the executive team in Tampere Water, Finland. She regularly gives lectures in courses and seminars organised by universities and other organisations.

Ari Jokinen, PhD, adjunct professor, is a university researcher at the School of Management, University of Tampere, Finland. He focuses on urban sustainability research from the perspectives of environmental policy, knowledge, strategies and the politics of nature. Recently, he studied how urban technologies take shape in urban regeneration and refresh policy choices in cities.

Professor Jukka Rintala has over 20 years of experience developing various biological technologies and concepts for resource recovery from wastewater and waste. He leads the Bio and circular economy research group, which belongs to the eco- and energy-efficiency profile area of the Tampere University of Technology. The group has lengthy and broad research and development experience in various biological and thermochemical processes, both in the laboratory and at full scale, as well as their integration in urban and industrial environments. 